\title{
Neurocritical care in aneurysmal subarachnoid haemorrhage: The evidence-based approach
}

\author{
Jeremy S. Dority
}

\section{INTRODUCTION}

Subarachnoid haemorrhage (SAH) is a devastating though relatively uncommon type of stroke with high morbidity, mortality and economic impact. Occurring with an incidence between 2 and 22/100,000 persons/year with regional variation, $\mathrm{SAH}$ accounts for about $5 \%$ of all strokes. In the United States, the incidence is about $10 / 100,000$ persons/year. ${ }^{[1]}$ Modern 30 days mortality is as high as $40 \%$, and about $50 \%$ of survivors suffer from permanent disability. Care at high volume centres with dedicated Neurointensive Care Units is recommended, although sub-specialty expertise may be more important than clinical volume. This article will focus on selected points of management of these critically ill patients with an emphasis on the newest understanding and care recommendations relevant to anaesthesiologists and neuro-intensivists.

\section{MANAGEMENT PRIOR TO ANEURYSM OBLITERATION}

The anaesthesiologist will typically be consulted after diagnosis of SAH has been made, and the patient is transported to the Intensive Care Unit or in preparation for aneurysm obliteration in the angiography or operating suite. Neurological examination, including mental status, is important, as anaesthesia will mask subtle changes. Ensuing compromise should be expected and plans developed for such occasion. Evaluation of the patient's ability to protect the airway as well as need for haemodynamic monitoring and control are paramount in this first assessment. An aneurysm that has caused an SAH can re-bleed. While the size of the aneurysm

Department of Anesthesiology, Division of Neuroanesthesia, University of Kentucky, Lexington, KY, USA

\begin{tabular}{|l|l|}
\hline \multicolumn{2}{|c|}{ Access this article online } \\
\hline Quick Response Code: & Website: \\
\hline & www.jnaccjournal.org \\
\hline & \\
\hline & \\
\hline
\end{tabular}

is the strongest predictor of rupture, re-bleeding of the aneurysm may be in part attributable to uncontrolled hypertension. A titratable agent, e.g., nicardipine, should be used to prevent extreme hypertension and specific blood pressure goals should be individualised based on a patient's age, cardiac history, baseline blood pressure and aneurysm size. Hypotension must also be avoided as it may compromise cerebral perfusion pressure and increase both the risk and size of stroke. INTERACT-2 demonstrated the safety of targeting systolic blood pressure $<140 \mathrm{mmHg}$ when compared to a target of $<180 \mathrm{mmHg}$. Similarly, intracerebral haemorrhage ADAPT compared a target of $<150-<180 \mathrm{mmHg}$ and did not find a reduction in blood flow on computed tomography (CT) perfusion. Our practice is to target systolic blood pressure $<140 \mathrm{mmHg}$ using nicardipine as the first-line agent. ${ }^{[2]}$ Antihypertensive Treatment of Acute Cerebral Haemorrhage-II, a multicentre, randomised, controlled, phase III trial has enrolled 1000 subjects and will evaluate intensive systolic blood pressure reduction to $140 \mathrm{mmHg}$ using nicardipine compared to $180 \mathrm{mmHg}$ in the control arm.

The aneurysm should be obliterated through neuro-interventional approaches or microsurgical clipping as early as feasible, as the risk of re-haemorrhage is up to $26 \%$ in the first 2 weeks without treatment. ${ }^{[3]}$

\section{NEUROCRITICAL CARE}

\section{Neurogenic pulmonary oedema}

Neurogenic pulmonary oedema is defined as any respiratory compromise that accompanies an acute neurologic insult that cannot be explained by co-existing cardiac or pulmonary derangement. ${ }^{[4]}$ Though a

This is an open access article distributed under the terms of the Creative
Commons Attribution-NonCommercial-ShareAlike 3.0 License, which allows
others to remix, tweak, and build upon the work non-commercially, as long as the
author is credited and the new creations are licensed under the identical terms.

For reprints contact: reprints@medknow.com

How to cite this article: Dority JS. Neurocritical care in aneurysmal subarachnoid haemorrhage: The evidence - based approach. J Neuroanaesthesiol Crit Care 2016;3:77-80. 
somewhat nebulous definition, this pathology can complicate an already tenuous clinical course for patients following SAH. It is estimated that up to $23 \%$ of SAH patients develop some form of pulmonary oedema with $2-8 \%$ being attributed to neurogenic pulmonary oedema. ${ }^{[4,5]}$ Of those patients who develop neurogenic pulmonary oedema, mortality rates have been reported as high as $50 \% .{ }^{[4]}$

The clinical presentation of neurogenic pulmonary oedema includes dyspnoea, tachypnoea, tachycardia, cyanosis, pink frothy sputum and crackles on auscultation of lung fields. Radiographic imaging reveals bilateral diffuse alveolar infiltrates. ${ }^{[4]}$ Both an early onset form and delayed onset form exist with early onset symptoms beginning within minutes to hours after the neurologic insult and late-onset symptoms typically declaring themselves by $12-24 \mathrm{~h}$ post-bleed. ${ }^{[4]}$

The pathophysiology behind neurogenic pulmonary oedema is not fully understood but is believed to be due to excess sympathetic nervous system activity. This sympathetic surge causes pulmonary venoconstriction with a concomitant rise in capillary permeability from the release of inflammatory cytokines that results in an increase in extravascular lung water and impaired oxygenation. ${ }^{[4,6]}$ It is also hypothesised that the lungs can suffer direct damage from release of inflammatory cytokines triggered by ischaemia to areas of the hypothalamus and medulla oblongata. ${ }^{[4]}$

Treatment for neurogenic pulmonary oedema is largely supportive. First, attention should be attributed to reducing intracranial pressure. Although hypervolemia was previously endorsed in the management of $\mathrm{SAH}$, the current trend in clinical practice is towards euvolemia. ${ }^{[5]}$ Lung protective measures such as low tidal volume, administration of positive end-expiratory pressure and titration of $\mathrm{FiO}_{2}$ to maintain oxygen saturation are recommended. ${ }^{[4]}$ Permissive hypercapnia, a lung protective technique often used in acute respiratory distress syndrome, should be avoided as this will exacerbate elevated intracranial pressure and potentially worsen the clinical situation.

New research in the treatment of neurogenic pulmonary oedema has targeted antagonism of the P2X7 receptor, an adenosine triphosphate-gated ion channel involved in cytotoxicity and apoptosis. ${ }^{[7]}$ Activation of the P2X7R receptor causes a cascade of cellular protein kinases that are instrumental in apoptosis. Blockade of these receptors is believed to provide neuroprotection in the setting of SAH. ${ }^{[7]}$ Brilliant blue G (BBG) is a drug currently undergoing study as a P2X7R receptor antagonist. BBG administered after SAH resulted in improved neurologic function and reduced brain oedema in rat studies. ${ }^{[7]}$ Specifically in relation to neurogenic pulmonary oedema,
BBG was found in a rat model to reduce pulmonary oedema by decreasing breakdown of the cellular tight junctions in the alveolar-capillary membrane. ${ }^{[8]}$ Human studies are lacking. Therefore, supportive treatment still stands as the primary form of management.

\section{Stress cardiomyopathy}

Cardiac complications following SAH are numerous. These include electrocardiogram changes (ST and T wave abnormalities, QT prolongation and U waves), ventricular and supraventricular arrhythmias, troponin elevation and myocardial dysfunction in the absence of coronary vasospasm. ${ }^{[9]}$ The incidence of arrhythmias is 35\% following SAH with roughly $5 \%$ being life-threatening. ${ }^{[5]}$ The reported incidence of the left ventricular wall motion abnormalities is $22 \%$ with troponin elevation found in $68 \%$ of patients post-bleed. ${ }^{[10]}$

Tako-tsubo cardiomyopathy is a unique form of cardiac dysfunction found in SAH patients. This syndrome consists of transient wall motion abnormalities of the left ventricle that are often triggered by extreme emotional or physical stress. ${ }^{[11]}$ Specifically, the apex of the left ventricle balloons outward with relative sparing of the basal segments. ${ }^{[12]}$

It is postulated that catecholamine surge could be responsiblefor the changes in the myocardium as evidenced by a greater concentration of adrenoreceptors in the left ventricular apex as compared to the base. ${ }^{[13]}$ Histologic evaluation of affected heart tissue reveals myocardial contraction band necrosis. ${ }^{[10]}$ Cardiac magnetic resonance imaging may also be used to differentiate tako-tsubo cardiomyopathy from other potential diagnoses such as myocarditis and myocardial infarction, which demonstrate delayed gadolinium enhancement. ${ }^{[14]}$

Treatment for tako-tsubo cardiomyopathy is largely supportive. Attempts should bemade tominimisemyocardial oxygen demand while maximising myocardial oxygen supplies. Arrhythmias should be treated promptly, and medications such as aspirin, nitrites, statins, beta-blockers, calcium channel blockers and angiotensin-converting enzyme inhibitors should be considered. Intra-aortic balloon pump counterpulsation may be needed to support severely decompensated patients. ${ }^{[12]}$

Complications associated with tako-tsubo cardiomyopathy include hypotension, arrhythmias, heart failure, ventricular rupture and thrombosis formation in the dilated left ventricular apex. ${ }^{[14]}$ These complications may increase morbidity, but the overall prognosis is good as the damage to the myocardium is typically reversible after 3-5 days without additional cardiac insult. ${ }^{[13]}$ In fact, most patients show improved systolic function in as little as 1 week with complete recovery in 3-4 weeks. ${ }^{[15]}$ 


\section{Pituitary dysfunction}

Pituitary dysfunction in the setting of SAH is underappreciated and can continue to affect patients' quality of life long after the acute phase of recovery. Khajeh et al., prospectively evaluated pituitary dysfunction in $\mathrm{SAH}$ at a single institution. ${ }^{[15]}$ In their study of 88 patients, $39 \%$ of survivors of $\mathrm{SAH}$ demonstrated at least one pituitary hormone deficiency, with gonadotropin or growth hormone deficiency occurring most frequently. Hydrocephalus was identified as an independent predictor of the $26 \%$ of patients who demonstrated persistent pituitary dysfunction at 6 months. It is possible that elevated intracranial pressure may cause direct damage by altering the anatomy of the hypothalamus-pituitary construct. Patients recovering from SAH often report symptoms of fatigue, impaired memory and planning and resulting decreased quality of life. These symptoms are similarly reported in patients with growth hormone deficiency. As such, restoration of normal anterior pituitary hormone levels could potentially improve rehabilitation and may warrant screening in select patients. ${ }^{[16]}$

\section{DELAYED CEREBRAL ISCHAEMIA}

Delayed cerebral ischaemia (DCI) is defined as the occurrence of focal neurological impairment or a decrease of at least two points on the Glasgow Coma Scale persisting for $1 \mathrm{~h}$ and not attributable to other causes. DCI occurs in up to $40 \%$ of patients surviving the initial haemorrhage and is the primary cause of mortality if it leads to infarction. Historically, DCI was thought to be due to cerebral vasospasm, and the terms were used nearly interchangeably. However, it is important to emphasise that while cerebral vasospasm can contribute to DCI, the two phenomena are not equivalent. The term vasospasm should be reserved for those patients with angiographic evidence of arterial narrowing and can be screened for with non-invasive daily transcranial Doppler assessment of cerebral blood flow velocities. While vasospasm is one potential cause of DCI, other pathomechanisms do occur. In $70 \%$ of patients with $\mathrm{SAH}$, angiographic evidence of vasospasm is seen but only up to $40 \%$ develop DCI. Furthermore, regions of hypoperfusion are observed in regions and patients without angiographic vasospasm. ${ }^{[17]}$

\section{THERAPIES}

\section{Euvolemic hypertensive therapy}

Hyperdynamic, hypertensive, haemodilutional therapy is no longer consistent with our understanding of SAH management and DCI. Specifically, prophylactic hypervolemia via the administration of colloids or crystalloids is not recommended and can worsen cardiopulmonary status. Euvolemia maintenance is critical however, and it appears that the hypertension component is the most important ' $\mathrm{H}$ '. Therefore, euvolemic hypertensive therapy is recommended for patients with DCI. ${ }^{[18]}$ Insufficient data exist to recommend iatrogenic haemodilution. Although clinical experience and anecdotes report reversal of signs of DCI with initiation of hypertension, randomised trials are still needed. The HIMALAIA trial is a multicentre, randomised, controlled trial that will compare hypertension induction to no blood pressure augmentation in the treatment of DCI. The primary focus will be on outcome, but CT perfusion studies assessing changes in cerebral blood flow will also be performed and may further refine our understanding of DCI. ${ }^{[19]}$

\section{Calcium channel blockers}

Oral nimodipine therapy is a mainstay of $\mathrm{SAH}$ management. Based largely on the landmark trial published in 1983 evaluating oral nimodipine, ${ }^{[20]} \mathrm{SAH}$ patients are routinely given oral $60 \mathrm{mg} \mathrm{q} 4 \mathrm{~h}$ for 21 days to reduce the rate of DCI and improve outcomes. Nimodipine administration is the only class 1, level A recommendation in the management of $\mathrm{SAH}$. In addition to its vasodilating effects mediated through inhibition of L-type calcium channels, nimodipine also appears to offer neuroprotection through fibrinolytic activity and inhibition of cortical spreading depolarisation. Another dihydropyridine calcium channel blocker, nicardipine, is used extensively in SAH patients for blood pressure control. Haley et al. ${ }^{[21]}$ showed reduced angiographic vasospasm, but no improvement in outcomes with intravenous nicardipine. Administration of intra-ventricular and intra-arterial nicardipine has also shown reduced evidence of vasospasm. ${ }^{[22]}$

\section{Statins}

SAH and secondary brain injury related to DCI involve a complex and incompletely understood inflammatory cascade. HMGC-oA reductase inhibitors (statins) have many effects that may be beneficial in SAH:

- Improve endothelial vasomotor function

- Increase nitric oxide availability

- Act as antioxidants

- Induce angiogenesis

- Suppress cytokines in cerebral ischaemia.

Statin therapy in SAH was shown to decrease DCI in small trials of pravastatin. Unfortunately, recent larger trials failed to show benefit. The simvastatin in aneurysmal SAH trial evaluated 800 patients given $40 \mathrm{mg}$ simvastatin versus placebo for 21 days and was unable to demonstrate improved short- or long-term outcomes. ${ }^{[23]}$ Pilot trials used higher dose simvastatin, so $80 \mathrm{mg}$ simvastatin was compared to $40 \mathrm{mg}$ but still 
failed to show any benefit in the high-dose simvastatin for aneurysmal SAH trial. ${ }^{[24]}$ Therefore, initiation of statin therapy to improve functional outcomes cannot be recommended for routine administration in SAH care.

\section{CONCLUSION}

SAH remains a terrible disease with high morbidity and mortality. Outcomes can be improved when care is provided at high volume centres with dedicated Neurointensive Care Units and specialised staff. Trials relating to virtually every component of management are still ongoing, with an emphasis on neuroprotective mechanisms and therapies. Through deliberate practice, adherence to evolving best evidence and developing understanding of secondary brain injury, progress will be made.

\section{Financial support and sponsorship Nil.}

\section{Conflicts of interest}

There are no conflicts of interest.

\section{REFERENCES}

1. de Rooij NK, Linn FH, van der Plas JA, Algra A, Rinkel GJ. Incidence of subarachnoid haemorrhage: A systematic review with emphasis on region, age, gender and time trends. J Neurol Neurosurg Psychiatry 2007;78:1365-72.

2. Woloszyn AV, McAllen KJ, Figueroa BE, DeShane RS, Barletta JF. Retrospective evaluation of nicardipine versus labetalol for blood pressure control in aneurysmal subarachnoid hemorrhage. Neurocrit Care 2012;16:376-80.

3. Kassell NF, Torner JC. Aneurysmal rebleeding: A preliminary report from the cooperative aneurysm study. Neurosurgery 1983;13:479-81.

4. Busl KM, Bleck TP. Neurogenic pulmonary edema. Crit Care Med 2015;43:1710-5.

5. Bruder N, Rabinstein A; Participants in the International Multi-Disciplinary Consensus Conference on the Critical Care Management of Subarachnoid Hemorrhage. Cardiovascular and pulmonary complications of aneurysmal subarachnoid hemorrhage. Neurocrit Care 2011;15:257-69.

6. Baker M, Bastin MT, Cook AM, Fraser J, Hessel E $2^{\text {nd }}$. Hypoxemia associated with nimodipine in a patient with an aneurysmal subarachnoid hemorrhage. Am J Health Syst Pharm 2015;72:39-43.

7. Chen S, Ma Q, Krafft PR, Chen Y, Tang J, Zhang J, et al. P2X7 receptor antagonism inhibits p38 mitogen-activated protein kinase activation and ameliorates neuronal apoptosis after subarachnoid hemorrhage in rats. Crit Care Med 2013;41:e466-74.

8. Chen S, Zhu Z, Klebe D, Bian H, Krafft PR, Tang J, et al. Role of P2X purinoceptor 7 in neurogenic pulmonary edema after subarachnoid hemorrhage in rats. PLoS One 2014;9:e89042.

9. D'Souza S. Aneurysmal subarachnoid hemorrhage.
J Neurosurg Anesthesiol 2015;27:222-40.

10. Wartenberg KE, Mayer SA. Medical complications after subarachnoid hemorrhage. Neurosurg Clin N Am 2010;21:325-38.

11. Kurisu S, Kihara Y. Tako-tsubo cardiomyopathy: Clinical presentation and underlying mechanism. J Cardiol 2012;60:429-37.

12. Lee K, Choi HA, Edwards N, Chang T, Sladen RN. Perioperative critical care management for patients with aneurysmal subarachnoid hemorrhage. Korean J Anesthesiol 2014;67:77-84.

13. Davison DL, Chawla LS, Selassie L, Tevar R, Junker C, Seneff MG. Neurogenic pulmonary edema: Successful treatment with IV phentolamine. Chest 2012;141:793-5.

14. Komamura K, Fukui M, Iwasaku T, Hirotani S, Masuyama T. Takotsubo cardiomyopathy: Pathophysiology, diagnosis and treatment. World J Cardiol 2014;6:602-9.

15. Khajeh L, Blijdorp K, Heijenbrok-Kal MH, Sneekes EM, van den Berg-Emons $\mathrm{HJ}$, van der Lely AJ, et al. Pituitary dysfunction after aneurysmal subarachnoid haemorrhage: Course and clinical predictors - The HIPS study. J Neurol Neurosurg Psychiatry 2015;86:905-10.

16. Jovanovic V, Pekic S, Stojanovic M, Tasic G, Djurovic B, Soldatovic I, et al. Neuroendocrine dysfunction in patients recovering from subarachnoid hemorrhage. Hormones (Athens) 2010;9:235-44.

17. Vergouwen $M D$, Vermeulen $M$, van Gijn J, Rinkel GJ, Wijdicks EF, Muizelaar JP, et al. Definition of delayed cerebral ischemia after aneurysmal subarachnoid hemorrhage as an outcome event in clinical trials and observational studies: Proposal of a multidisciplinary research group. Stroke 2010;41:2391-5.

18. DankbaarJW, Slooter AJ, Rinkel GJ, Schaaf IC. Effect of different components of triple-H therapy on cerebral perfusion in patients with aneurysmal subarachnoid haemorrhage: A systematic review. Crit Care 2010;14:R23.

19. Gathier CS, van den Bergh WM, Slooter AJ; HIMALAIA-Study Group. HIMALAIA (Hypertension Induction in the Management of AneurysmaL subArachnoid haemorrhage with secondary IschaemiA): A randomized single-blind controlled trial of induced hypertension vs. no induced hypertension in the treatment of delayed cerebral ischemia after subarachnoid hemorrhage. Int J Stroke 2014;9:375-80.

20. Allen GS, Ahn HS, Preziosi TJ, Battye R, Boone SC, Boone SC, et al. Cerebral arterial spasm - A controlled trial of nimodipine in patients with subarachnoid hemorrhage. $\mathrm{N}$ Engl J Med 1983;308:619-24.

21. Haley EC Jr., Kassell NF, Torner JC. A randomized trial of nicardipine in subarachnoid hemorrhage: Angiographic and transcranial Doppler ultrasound results. A report of the cooperative aneurysm study. J Neurosurg 1993;78:548-53.

22. Lu N, Jackson D, Luke S, Festic E, Hanel RA, Freeman WD. Intraventricular nicardipine for aneurysmal subarachnoid hemorrhage related vasospasm: Assessment of 90 days outcome. Neurocrit Care 2012;16:368-75.

23. Kirkpatrick PJ, Turner CL, Smith C, Hutchinson PJ, Murray GD; STASH Collaborators. Simvastatin in aneurysmal subarachnoid haemorrhage (STASH): A multicentre randomised phase 3 trial. Lancet Neurol 2014;13:666-75.

24. Wong GK, Chan DY, Siu DY, Zee BC, Poon WS, Chan MT, et al. High-dose simvastatin for aneurysmal subarachnoid hemorrhage: Multicenter randomized controlled double-blinded clinical trial. Stroke 2015;46:382-8. 